\title{
Dynamics of the swash zone and effluent line on sandy beaches
}

\author{
Susan B. McArdle, Anton McLachlan \\ Department of Zoology, University of Port Elizabeth, PO Box 1600, Port Elizabeth 6000, South Africa
}

\begin{abstract}
Features of overall swash climate were examined over a range of beaches including reflective, intermediate and dissipative types. Both reflective and dissipative beaches have swashes, with respectively short and long periods, that cross the effluent line or groundwater table outcrop at all states of the tide. Intermediate beaches experience more swashes crossing the effluent line at high tide. Total swash upwash is greatest on intermediate beaches whereas the frequency of upwashes reaching unsaturated sand above the effluent line is greatest on reflective beaches. The 3 beach types are well separated on the basis of total upwash distance as a percentage of intertidal distance, this being 95 to $125 \%$ on reflective beaches, 25 to $55 \%$ on intermediate and 7 to $35 \%$ on dissipative beaches. Similarly, reflective beaches are marked by 2 to 5 effluent line crossings $\min ^{-1}$ as opposed to 0 to 2 for intermediate and 0 to 1 for dissipative beaches. Many features of swash climate show good correlations with beach slope and morphodynamic state but not with wave energy. All beach types exhibit similar proportions of saturated vs unsaturated sand, this being 5 to $30 \%$ at low tide and 80 to $95 \%$ at high tide. It is concluded that changes in the dynamics of the effluent line and swash climate from reflective to dissipative beach types may be responsible for changes in interstitial conditions and the types of macrofauna inhabiting the different beaches.
\end{abstract}

\section{INTRODUCTION}

The dynamics and position of the effluent line, which separates saturated and unsaturated sand, on sandy beaches are of great importance both physically and ecologically in that they can determine the extent of swash water filtration through a particular beach (McLachlan 1982) and the point above which macrofauna are unable to burrow. The surface of the beach face downshore of the effluent line is saturated, giving the 'glassy layer' common to sandy beaches. The swash is able to penetrate the beach face only when it flows over unsaturated sand above the effluent line. This infiltration of the swash into the sand creates a localised rise in the water table level, and hence the effluent line moves up the beach face (Waddel 1976). Seepage causes a corresponding fall of the water table and a retreat of the effluent line down the beach, though there is a time lag in both of these responses. Individual swashes cause water table fluctuations in the immediate vicinity of the swash zone whereas long standing waves or tides are of larger magnitude and are transmitted further into the beach (Waddel 1976). Further information on these swash zones is given in McArdle \& McLachlan (in press).
The mechanism and measurement of swash water filtration were first described by Riedl (1971) and Riedl \& Machan (1972), who showed it to be significant in processing large volumes of seawater through sandy beaches. Subsequently, McLachlan $(1979,1982,1989)$ and McLachlan et al. (1985) quantified these inputs over a range of beaches in South Africa, Western Australia and North America. The general trend is an increase in the volume of water filtered and a decrease in residence time from flat dissipative to steep reflective beaches. Further, the primary driving force changes from tide-induced to wave-induced. Infiltration only occurs above the effluent line or saturated sand and thus reflective beaches with effluent lines and water tables at low tidal levels filter the greatest volumes. Central to this model is the slope as key distinguishing feature between beach types (McLachlan 1990).

Both the interstitial fauna and the macrofauna of sandy beaches are directly affected by the swash processes: the former by infiltration, which is responsible for flushing oxygen and organics into the sand (McIntyre et al. 1970), and the latter by the swash dynamics and the position of the effluent line, which influence tidal migrations and burrowing (Shepherd 1985, 
McLachlan 1990). The macrofauna occupy a dynamic habitat and the position of the effluent line is of particular importance to burrowing organisms such as the bivalves Donax and Bullia spp. Donax spp. for example, are unable to burrow into unsaturated sand (Ansell \& Trueman 1973). The position of the effluent line, therefore, limits their tidal migration.

Research on the intertidal zonation of macrofauna on sandy beaches has attempted to isolate the factors affecting the distribution of macrofauna (Salvat 1964, 1966, 1967, Bally 1983). However, the distribution and abundance of macrofauna have not been related to the dynamic properties of a sandy beach, with the exception of the study of Shepherd (1985). He examined the distribution of the southern mole crab Hippa australis in relation to tide, incident waves and swash interactions, as well as to changes in beach face morphology. Ansell \& Trueman (1973) linked the burial speed of Donax spp. to the swash period. On steep beaches with short swash periods Donax spp. tend to adopt a much faster burial rate than on more gently sloping beaches.

Bally (1983) and McLachlan (1983) attempted to compile a general picture of how abundance and diversity were linked with the dynamics or morphodynamics of sandy beaches. McLachlan et al. (1981) obtained significant correlations between macrofauna species richness and abundances and both grain size and beach slope. In a more recent study, McLachlan (1990) expanded this to a global model and concluded that the type of fauna developing on a beach is primarily determined by the total swash 'climate' of the beach face.

The aim of the present study was to quantify the dynamics of the effluent line in association with general swash characteristics over a tidal cycle for a range of beach types. We also hoped to demonstrate the relationship between the swash climate and the dynamics of the effluent line with changing physical conditions, and to assess the proportion of saturated or unsaturated beach at different stages of the tide. It was hoped that the findings of this study would explain some of the variation of beach macrofauna community structure. A previous paper (McArdle \& McLachlan in press) concentrated on individual swashes; here we examine the total swash patterns.

\section{STUDY AREAS}

Beaches. Field data were collected in 2 geographical areas - southern Africa and the west coast of the USA. Detailed information of study sites is included in McArdle \& McLachlan (in press). Ten beaches from the latter study were selected as representative of reflective, intermediate and dissipative (Short \& Wright 1983) conditions. Reflective beaches are steep with coarse sand and low wave energy, no surf zones and often small tide ranges. Dissipative beaches are flat with fine sand, high wave energy, wide surf zones and often large tide ranges. Intermediate beaches fall between these 2 extremes. The reflective and intermediate beaches were located in South Africa and the dissipative beaches in the USA. The beaches which had been sampled most frequently in the initial study (McArdle \& McLachlan in press) were chosen in this study.

The beaches selected were: ST1 \& 2 (reflective); BF1 \& 2 and SR1, 2 \& 5 (intermediate); and TM2 and WR1 \& 2 (dissipative). The reflective beach was located on the west coast of South Africa and all the intermediate beaches on the south coast. Stompneusbaai (ST) occurs within the confines of St. Helena Bay and is a small sheltered beach well protected from westerly and southerly swells. BF1 is located $2.5 \mathrm{~km}$ and BF2 $250 \mathrm{~m}$ from the sheltered southwest corner of Buffalo Bay, BF1 being the more exposed of the 2 sites. SR is located in Algoa Bay and is subjected to strong wave action with waves breaking 200 to $300 \mathrm{~m}$ offshore (Wendt \& McLachlan 1985). South African tides are semidiurnal with a mean spring range of $1.6 \mathrm{~m}$ (McLachlan et al. 1981) and a maximum of $2.1 \mathrm{~m}$. The beaches on the Oregon coast in the northwest USA are modally dissipative, facing directly into the North Pacific. Threemile Beach (TM) is a very exposed beach and Whisky Run (WR) less exposed, both situated in southern Oregon. Tides are mixed, with a maximum daily range of $3.6 \mathrm{~m}$ and a mean range of about $2 \mathrm{~m}$ (Komar et al. 1976).

\section{METHODS}

At each site a transect was set up perpendicular to the shoreline. The limits of the transect were the previous high water mark and a point below low water. Numbered poles $2 \mathrm{~m}$ long were erected at $5 \mathrm{~m}$ intervals and $1 \mathrm{~m}$ long poles at $1 \mathrm{~m}$ intervals. The swash was measured continuously for 15 min per hour over a tidal cycle (12 h) by recording the time and position of the swash line on the transect. The time and position at which swashes crossed the effluent line were also noted.

Concurrent with the swash measurements, wave height and period and wind speed and direction were recorded at hourly intervals. The beach profile was surveyed from high water to below low water and grain size analysis was carried out on samples from low, mid and high tide. Swash zone slope was calculated for each hour of the tidal cycle from the beach profile and swash limits for each period. Swash speed was estimated from swash distance and time.

Swash profiles for 3 beaches representing the 3 main 
beach types were plotted to give a general view of the swash climate on each beach type. The data used in the rest of the study included the swash distance readings and the effluent line crossings. The variables used are listed below and will hereafter be referred to by their abbreviated titles.

Upwash distance: the sum of upwash distances for all swashes.

Unsaturated upwash: the sum of the distances of the upwashes which occurred on unsaturated sand, i.e. above the effluent line.

$\%$ unsaturated upwash: total unsaturated upwash as a percentage of total upwash distance.

Upwash to intertidal: total upwash distance per minute as a percentage of the intertidal distance. The latter was calculated as the difference between the upper and lower limits of the swash during a particular tidal cycle.

Unsaturated upwash to intertidal: total upwash crossing unsaturated sand per minute as a percentage of the intertidal.

Effluent line crossings: number of times the upwash crossed the effluent line per minute.

The above variables were plotted against Dean's parameter ( $\Omega$; Dean 1973), beach slope and wave height. $\Omega$ is calculated using wave-sediment characteristics. This dimensionless parameter is defined as [wave height $(\mathrm{cm}) /$ settling velocity $\left(\mathrm{cm} \mathrm{s}^{-1}\right) \times$ wave period(s)]. Wright et al. (1982) have defined beaches in southern Australia as dissipative when $\Omega>6$, as intermediate when $\Omega$ is between 1 and 6 and as reflective when $\Omega<1$. The same criteria were used in this study with the exception that ST1, which had an $\Omega$ value of 1 , was considered reflective, and TM2, with an $\Omega$ value of 6 , was considered dissipative. The reason for this selection was that ST is reflective and TM dissipative most of the time. Linear, multiplicative, exponential and reciprocal regression models were fitted for each pair of variables. For consistency the linear model was selected in each case with the exception of 2 cases where other models provided significantly much better fits than linear models.

The percentage of unsaturated and saturated beach was calculated from the area of beach above or below the effluent line as plotted on the swash profiles for 5 beaches representing a range of beach states. The 5 beaches (ST1, BF2, SR2, TM2 and WR1) gave a range of $\Omega$ between 1.0 and 9.4 . The effluent line in this case was taken as the leading edge of the swash.

\section{RESULTS}

Fig. 1 illustrates the general trend in the swash profiles and effluent lines of beaches representing 3 mor- phodynamic types: reflective (ST1), intermediate (SR2) and dissipative (WR1). Profiles for low, mid and high tide have been included except for ST1 and SR2, where mid tide values are omitted due to the overlap of the swash profiles with those from low and high tide. The reflective beach is characterised by short, frequent swashes (Fig. 1A) and an intertidal zone $30 \mathrm{~m}$ wide The jagged curve shows the changing position of the boundary between the subaqueous and the subaerial parts of the beach. For example, on the ebb tide the line of outcrop of the water table slowly shifts seaward but is intermittently moved landward again when a swash runs further up the beach. The effluent line closely follows the upper swash profile, with most swashes either reaching or crossing the effluent line.

SR2, an intermediate beach type (Fig. 1B), differs from the reflective beach in that the swashes are longer and less frequent and the intertidal zone is ca $90 \mathrm{~m}$ wide. The position of the effluent line appears to be more stable and is influenced by fewer swashes at high tide and none at low tide.

On the dissipative beach (Fig. 1C) the swashes are longer and less frequent than on the other beaches and the intertidal is wider, in this case $270 \mathrm{~m}$. The response of the effluent line is slow and it is crossed by few swashes. Swash crossings differ little between low and high tide.

'Upwash distance' (Fig. 2A) is highest for intermediate beaches ( 26 to $46 \mathrm{~m} \mathrm{~min}^{-1}$ ) and lowest for dissipative beaches ( 12 to $30 \mathrm{~m} \mathrm{~min}^{-1}$ ). The high values for intermediate beaches are probably a result of both relatively long swashes and short swash periods. Although refelctive beaches are subjected to short swash periods of less than $12 \mathrm{~s}$ (McArdle \& McLachlan in press) the individual upwash distances are short (mean $=6.5 \mathrm{~m}$ ) and the overall distance therefore reduced. There does not appear to be a relationship between upwash distance and tidal state.

There is an increase in 'Unsaturated upwash' from dissipative through intermediate to reflective beaches (Fig. 2B). The reflective beaches show great fluctuations, ranging from 3.3 to $6 \mathrm{~m} \mathrm{~min}^{-1}$, with no obvious relationship with tidal cycle, whereas there is a tendency for the unsaturated upwash to increase at high tide for both intermediate and dissipative beaches especially the former. In the case of intermediate beaches the range during low tide is 0 to $3 \mathrm{~m} \mathrm{~min}^{-1}$ and during high tide 3 to $6 \mathrm{~m} \mathrm{~min}^{-1}$. For dissipative beaches during low tide the range is 0 to $20 \mathrm{~m} \mathrm{~min}^{-1}$ and during high tide 0.5 to $3 \mathrm{~m} \mathrm{~min}^{-1}$.

The '\% unsaturated upwash' (Fig. 2C) follows a similar pattern to unsaturated upwash, with the possible exception that in Fig. $2 \mathrm{C}$ there is a more marked separation of reflective and intermediate beaches. A good separation of reflective, intermediate and dissipa- 

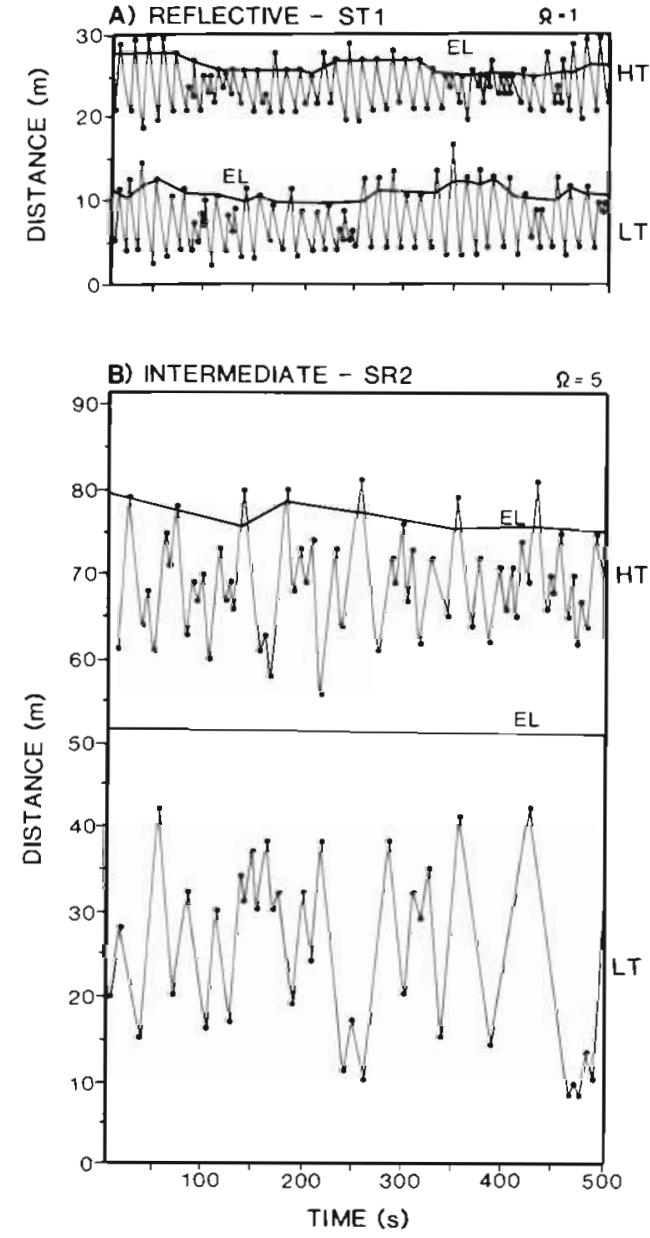

C) DISSIPATIVE - WR1

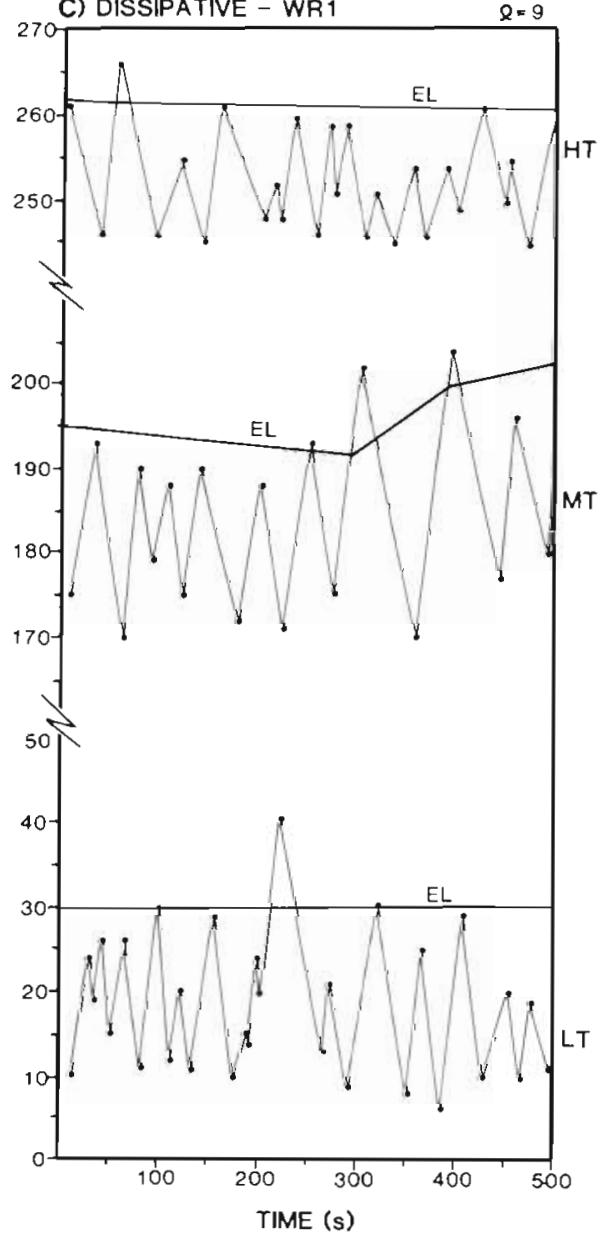

$E L=E F F L U E N T$ LINE

LT $=$ LOW TIOE

$M T=$ MID TIDE

HT $=$ HIGH TIOE
Fig. 1 Swash profiles for a typical (A) reflective (ST1), (B) intermediate (SR1) and (C) dissipative beach (WR1) Distance is relative to low water mark tive beaches was obtained using 'Upwash to intertidal' (Fig. 2D), with only a slight overlap between the intermediate and dissipative beach types. For reflective beaches values were recorded of 95 to $125 \%$, with intermediate 25 to $55 \%$ and dissipative 7 to $35 \%$, i.e. reflective beaches have the greatest amount of upwash in terms of intertidal distance available. There is no clear change in this over the tidal cycle.

'Unsaturated upwash to intertidal' shows a similar pattern to that of upwash to intertidal (Fig. 2E). For reflective beaches values were recorded of 10 to $20 \%$, intermediate 0 to $7 \%$ and dissipative 0 to $2 \%$. Values were extremely small for dissipative beaches and increased towards reflective conditions. There was an increase over high tide for intermediate beaches, probably due to the more reflective nature of the beach face at such times.

'Effluent line crossings' for reflective beaches range from 2.3 to $4 \mathrm{~min}^{-1}$ (Fig. $2 \mathrm{~F}$ ) with no correlation between number of crossings and state of tide. Values for intermediate beaches ranged from 0 to $2 \mathrm{~min}^{-1}$, with an increase towards high tide. This pattern is more distinct if the data for each study per site are examined separately. For example, at $B F 1$ there is a gradual increase from $0.07 \mathrm{~min}^{-1}$ crossing at low tide through $0.8 \mathrm{~min}^{-1}$ at mid tide to $1.5 \mathrm{~min}^{-1}$ at high tide. The number of crossings for dissipative beaches (Fig. 2F) was less than 1 min $^{-1}$ with a tendency to increase towards high tide.

When plotted against the reciprocal of slope (Fig. 3A to $F$ ) all of the swash variables (averaged over a tidal cycle) show a negative correlation in that as slope decreases so do the various swash measurements and effluent line crossings. With the exception of upwash distance correlation coefficient were greater than 0.86 for all variables, the maximum value of $r$ being 0.96 for number of effluent line crossings (Fig. 3F). These results are in contrast to those for individual swash readings where a decrease in slope results in an increase in the distance of an individual swash (MCArdle \& McLachlan in press).

When the swash and effluent variables are plotted against $\Omega$ (Fig. $3 G$ to $L$ ) there is a similar pattern as for slope in that the more dissipative the beach the lower the swash readings and number of effluent crossings. 

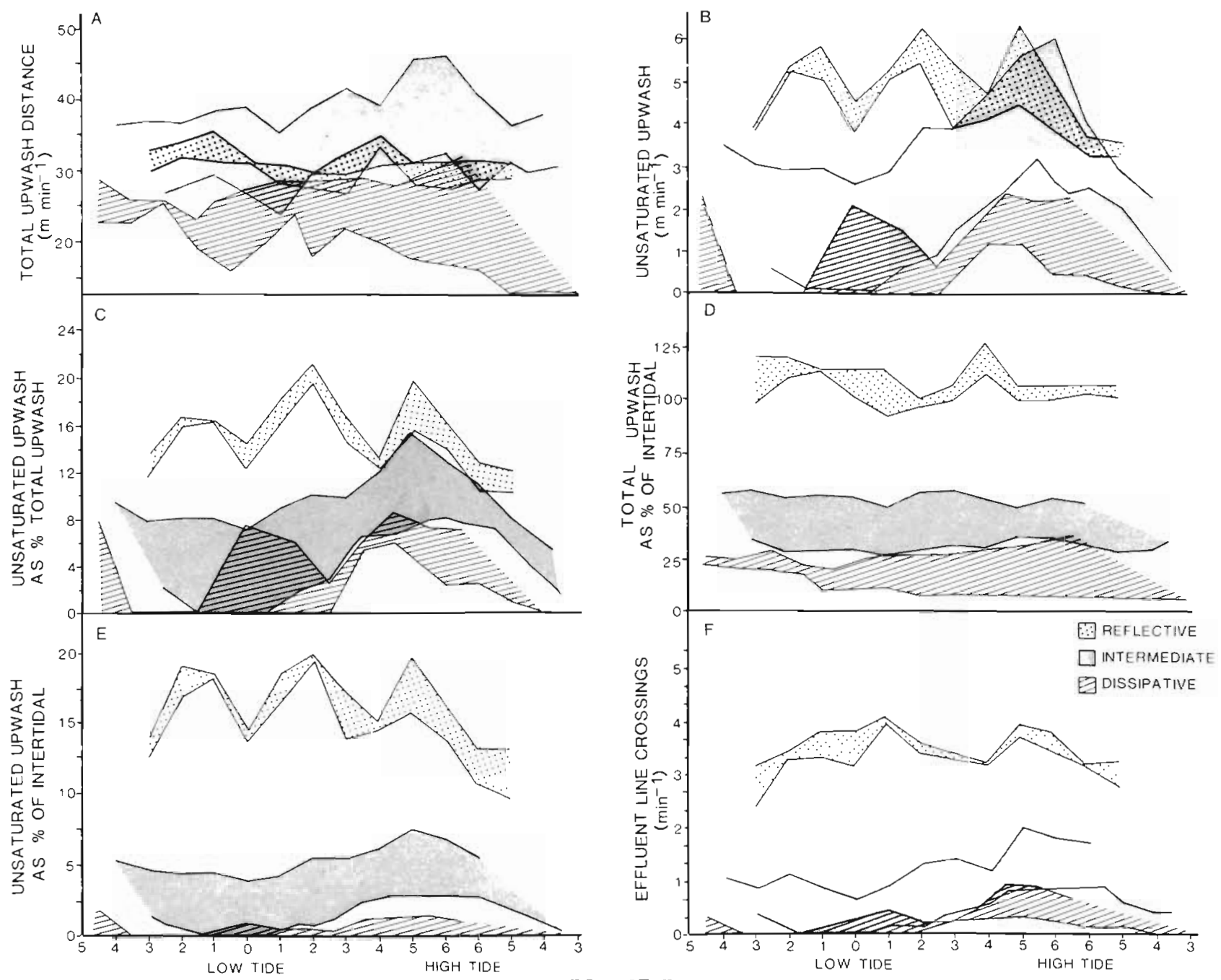

Fig. 2. Variation in (A) total upwash, (B) unsaturated upwash, (C) unsaturated upwash as a \% of total upwash, (D) total upwash and $(E)$ unsaturated upwash as \% of intertidal distance, (F) number of effluent line crossings over a tidal cycle

Correlation coefficients of greater than 0.7 were obtained for all variables with the exception of total upwash distance (Fig. 3G).

There was no significant correlation between wave height and upwash distance, unsaturated upwash or \% unsaturated upwash (Fig. 3M to O). The highest correlation coefficient of 0.77 was obtained for effluent line crossings (Fig. 3R).

The percentage of beach saturated at low, mid and high tide is plotted in Fig. 4 for beaches ST1, BF2, SR2, TM2 and WR1, which represent a range of $\Omega$ values from 1.0 to 9.4 . The percentage of beach which is saturated increases from low to high tide for all beaches as would be expected due to the rise of the tide and the effluent line. The percentage of beach saturated is fairly constant across all beaches, i.e. 5 to $30 \%$ at low tide and ca 80 to $95 \%$ at high tide. Therefore, when calculated as a percentage of intertidal distance, all beaches record a similar trend for unsaturated and saturated proportions, irrespective of morphodynamic state.

Plotting the area of beach unsaturated and saturated reveals a different pattern as a consequence of the great differences in beach width (Fig. 5). With the exception of BF2, there is a gradual increase in intertidal distance with increase in $\Omega$, i.e. from reflective to dissipative conditions. There is, as in Fig. 4, an increase in area of beach saturated from low to high tide for all beaches. On comparing the reflective ST1 and dissipative WR1 during high tide, there is ca 12 times more beach saturated at WR1 than at ST $1\left(253 \mathrm{~m}^{2}\right.$ and $21 \mathrm{~m}^{2}$ per $m$ respectively), with the intermediate beaches recording values of 63 to $94 \mathrm{~m}^{2} \mathrm{~m}^{-1}$. The contrast between the area saturated for reflective and dissipa- 

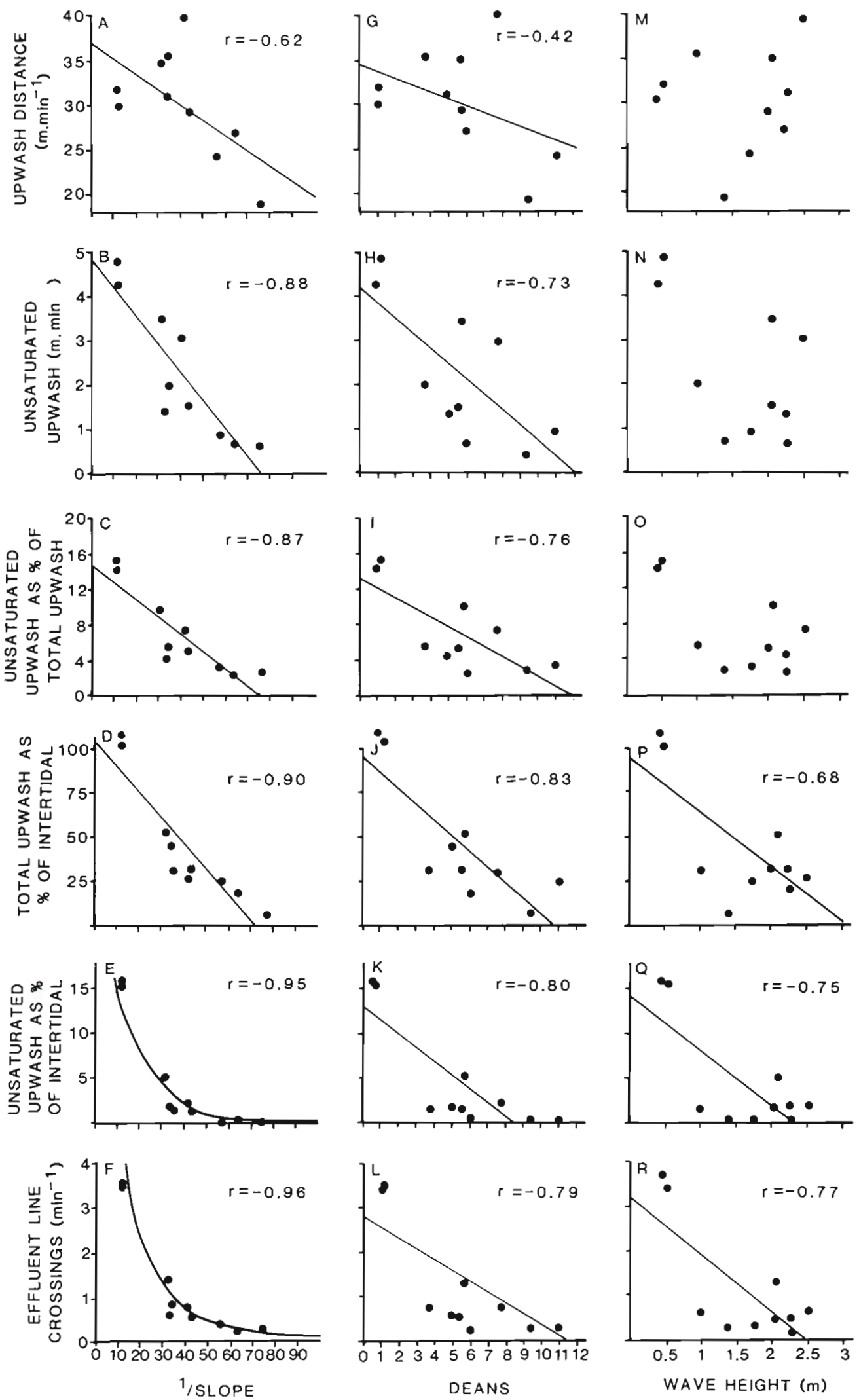

Fig. 3. Relationship of swash variables and effluent line crossings with (A to F) beach slope, ( $G$ to $L$ ) Dean's parameter $\Omega$ and ( $M$ to R) wave height. Beach slopes steeper than $1 / 20$ indicate reflective beaches and flatter than $1 / 50$ dissipative 

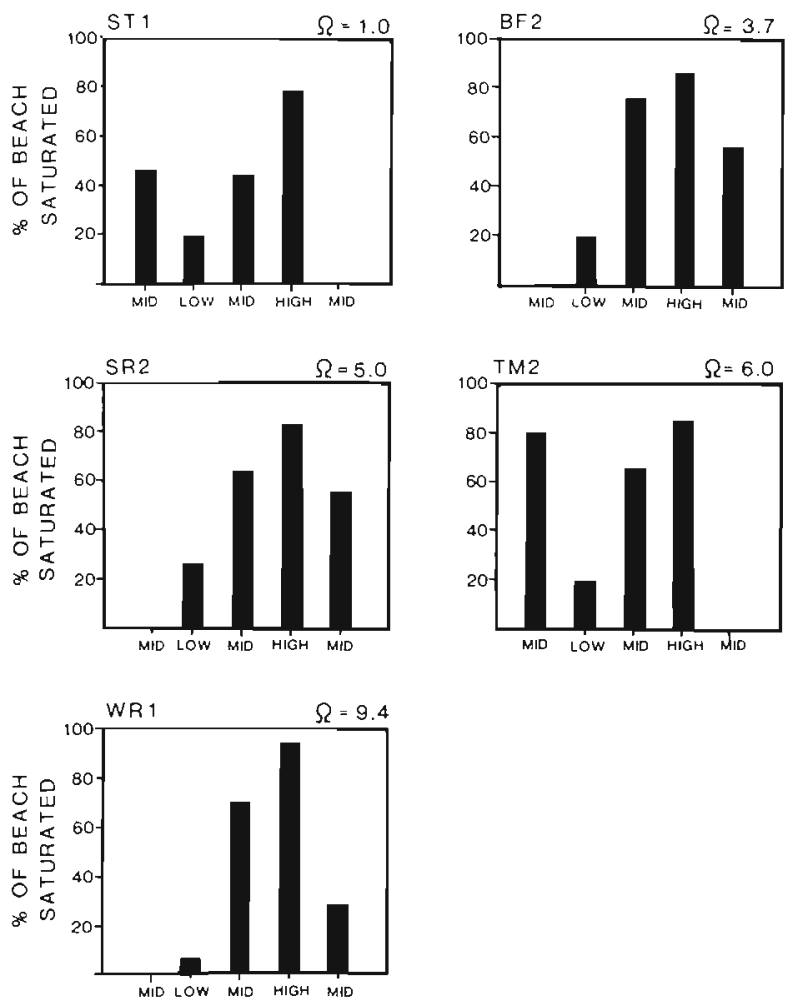

Fig. 4. Percentage of beach saturated at low, mid and high tide for a range of beach types
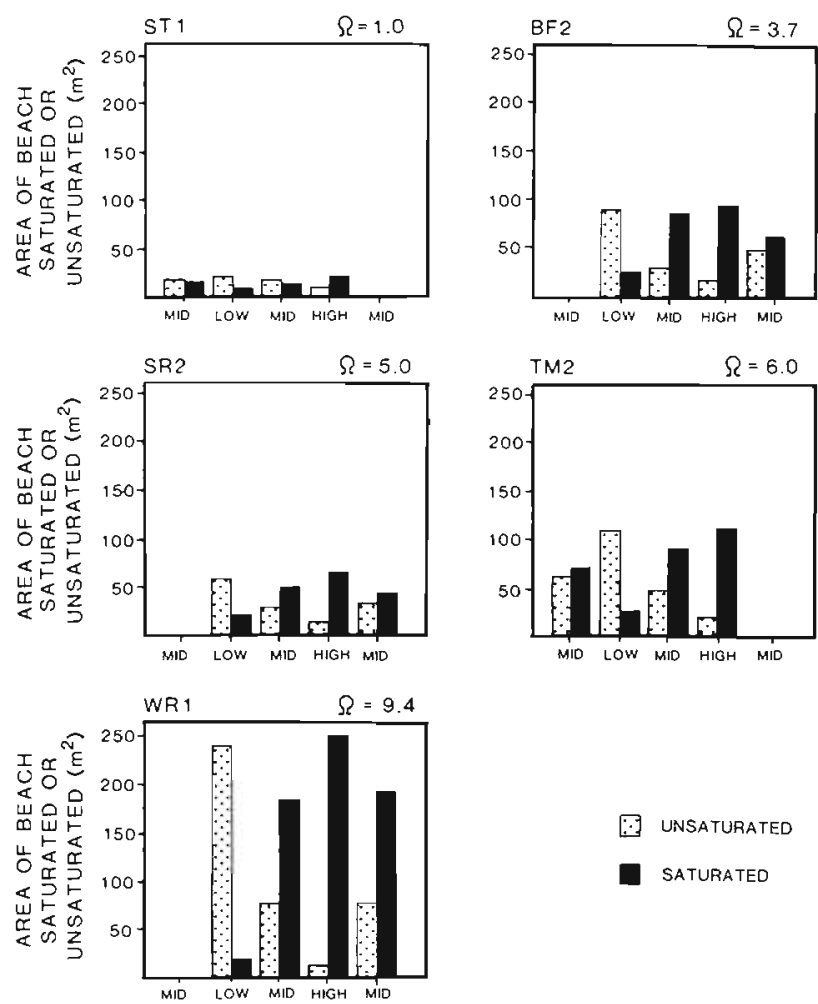

R. UnSATURATED

- saturated

Fig. 5. Area $\left(\mathrm{m}^{2} \mathrm{~m}^{-1}\right)$ of beach saturated and unsaturated at low, mid and high tide for a range of beach types. $\Omega$ : Dean's parameter tive beaches is highlighted by the fact that the values obtained for WR1 (dissipative) at low tide and ST1 (reflective) at high tide differ by only $0.22 \mathrm{~m}^{2}$.

\section{DISCUSSION}

The independent variables which correlate best with the features of swash climate investigated in this paper were firstly beach slope and secondly Dean's parameter $\Omega$. The advantage of using slope is that it can be measured simply with little error. However, it changes with wave climate. $\Omega$ is also reliable, but using wave period and wave height in its calculation induces some degree of error unless accurate wave data are available. Wave height on its own is not a reliable variable with which to estimate swash climate, a consequence of both the degree of error in estimating wave height and the variability that may occur even on one day.

Reflective, intermediate and dissipative beaches can be classified by various aspects of the swash climate, for example percentage of beach saturated at various states of the tide and number of effluent line crossings. They can also be classified by physical parameters such as slope or $\Omega$. Reflective beaches have short, frequent swashes, a narrow intertidal, a high frequency of swashes crossing the effluent line and a high percentage of upwash above the effluent line. Dissipative beaches have the reverse conditions, i.e. long, infrequent swashes and few effluent line crossings. Intermediate beaches fall between these 2 extremes.

The dynamics of the swash climate and the effluent line result in an increase in saturation of the beach from reflective to dissipative conditions and subsequently a decrease in the filtration of seawater through the sand, i.e. reflective beaches have maximum infiltration whereas dissipative beaches have low infiltration and high levels of saturation. These 2 factors, which are a direct result of the associated swash climate and beach slope, have major implications for the fauna. Dissipative beaches will have more stagnant interstitial conditions with lower oxygen tensions and steeper chemical gradients, whereas reflective beaches will have dynamic interstitial conditions with strong flushing, high oxygen and physical rather than chemical gradients.

Bally (1981), looking for trends in macrofauna distribution across a range of beaches, was not able to demonstrate any quantitative relationship or single out key parameters. McLachlan (1990) subsequently indicated that a number of variables influenced the fauna, but that regressions for $\Omega$ and slope showed a better fit than isolated factors such as particle size or wave action, the general conclusion being that the control of beach fauna is complex and determined by the overall morphology and dynamics of a beach. 
Apart from air-breathing crustaceans around the drift line, most sandy beach macrofauna are only active, and can only burrow, when on thixotropic sand, i.e. sand that is nearly or fully saturated. This occurs around and below the effluent line. The position of the effluent line at any point in the tidal cycle thus determines the proportion of the beach face on which active movement and foraging are possible. Towards the dissipative extreme the proportion and frequency of swash activity above the effluent line decreases, thereby reducing the risk of animals being swept or stranded above the effluent line where they may be unable to burrow. Thus the risks of living on an exposed beach may be reduced if the beach is flat and dissipative.

In this study and also McArdle \& McLachlan (in press) the swash climate and dynamics of the effluent line have been quantified and correlations have been obtained between beach slope and effluent line crossings, and a number of swash variables. No macrofaunal data is available for the present study, but the results suggest that the good negative correlation between beach slope and species diversity and abundance of macrofauna (McLachlan 1990) is the result of the swash climate associated with beach type and not slope per se.

The new sandy beach environmental parameters mentioned in this study can indirectly be related to changes in macrofauna by combining the results of the present study with that of McLachlan (1990). It is not possible to do direct correlation analysis between the swash and effluent line data in this paper and the faunal data of McLachlan (1990), since the studies have only a minority of beaches in common and, further, a single beach may have different swash and effluent line patterns on different days in response to different wave conditions. However, a composite plot (Fig. 6) of some faunal parameters (species richness, total abundance and mean individual mass; after McLachlan 1990) swash periods (after McArdle \& McLachlan in press) and effluent line crossings and \% unsaturated upwash (this paper) against beach slope indicates the parallel trends in all cases. Species richness and total abundance of the benthic macrofauna increase and mean individual mass decreases as beaches become flatter and more dissipative with longer swash periods, fewer effluent line crossings, a smaller proportion of the upwash on unsaturated sand, etc.

The close relationships between all these parameters is not taken as proof of cause and effect relationships, but merely as an indication that as beach type and beach face slope change there are parallel changes in swash and beach face processes and in faunal size, abundance and diversity. Beach slope itself is not the direct cause of faunal changes - even the most sluggish molluscs experience no difficulty in ascending the

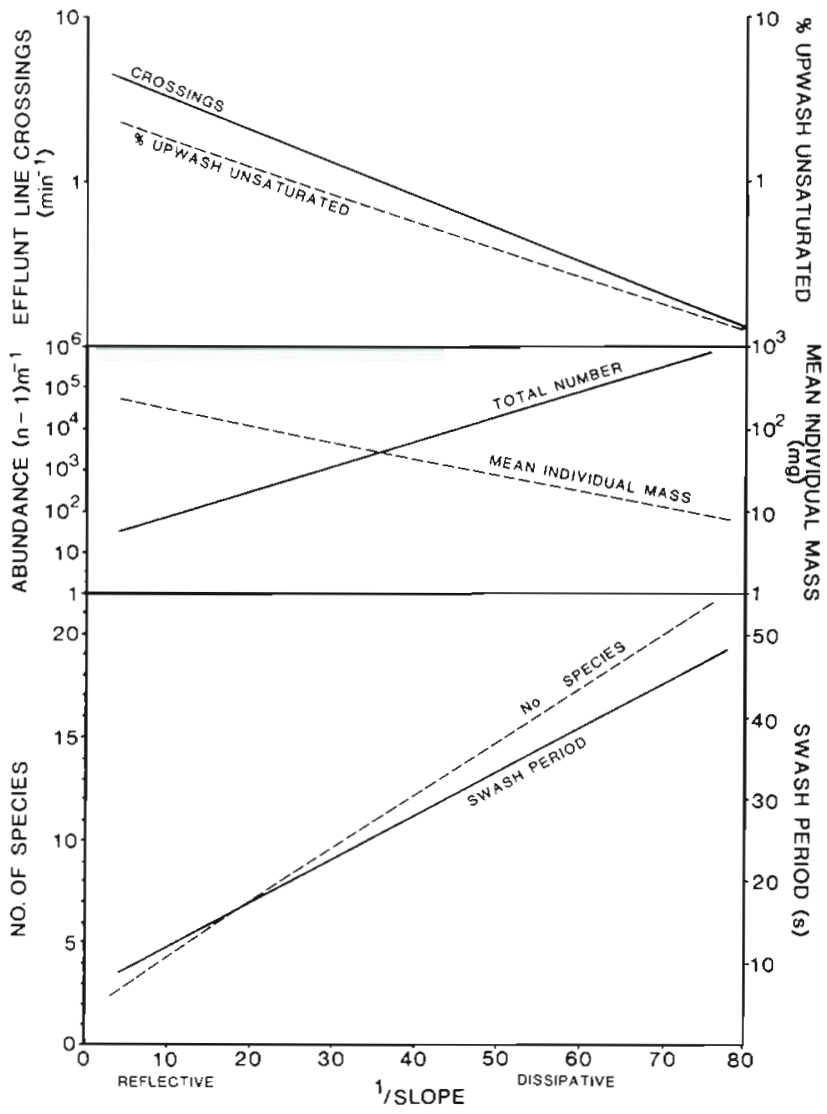

Fig. 6. Changes in swash, beach face and faunal parameters in response to changes in beach slope. The equations are: Swash period $=0.26(1 /$ slope $)+1.7, r^{2}=0.69, n=46$ (McArdle \& McLachlan in press). No. species $=0.26(1 /$ slope $)+1.7, r^{2}=$ $0.83, n=23$ (McLachlan 1990). Abundance: $\log (n+1)=0.06$ $(1 /$ slope $)+1.27, \mathrm{r}^{2}=0.76, \mathrm{n}=23$ (McLachlan 1990). Mean individual mass: $\log$ (ind. Biomass) $=0.02(1 /$ slope $)-0.53$. $\mathrm{r}^{2}=0.20, \mathrm{n}=21$ (McLachlan 1990). Crossings $=5.01$ $(1 / \text { slope })^{-1.53}, \mathrm{r}^{2}=0.92, \mathrm{n}=10$ (this paper). \% Unsaturated upwash $=e^{3.41+(0.074(1 / \text { slope }))}, \mathrm{r}^{2}=0.90, \mathrm{n}=10$ (this paper)

steepest slopes of $1 / 10$. It is a combination of the swash and beach face dynamics as a whole that influence the fauna.

McLachlan (1990) argued that longer (in distance and period) swashes on dissipative beaches create conditions which are better for animals to move and feed. Mean swash periods for reflective (ST1) and dissipative (TM1) beaches were $12 \mathrm{~s}$ and $59 \mathrm{~s}$ respectively (McArdie \& McLachlan in press). Molluscs subjected to swash periods of less than 10 to $20 \mathrm{~s}$ usually cannot respond fast enough in terms of burrowing time to burrow in between swashes, and are therefore in danger of being swept away or stranded on the drift line on reflective beaches (Brown 1982, McLachlan \& Young 1982, Ansell \& Trueman 1983). Dissipative beaches are more conductive to slow burrowers and small, less robust species. In this study total upwash distance was great- 
est for intermediate beaches, which further suggests that it is not the overall upwash that is important to the fauna but swash distance and period.

Having identified the key parameters of the swash climate which may be conducive to an increase in species diversity and abundance over a range of beaches, it is important that isolated factors such as swash speed, swash period and beach slope be examined experimentally to quantify the influence of each.

It is unlikely that a single feature of swash climate or beach face dynamics will explain all the faunal changes and adaptations encountered over a range of beach types. We expect that this suite of factors as a whole, the beach face 'climate' as experienced by the macrofauna, will be important. This paper has examined one aspect of beach face 'climate', interactions between swash and the effluent line. Subsequent work will investigate faunal responses.

Acknowledgements. We acknowledge the financial support of a C.S.I.R. Postdoctoral Fellowship to the first author during the course of this study. Assistance was also received through a C.S.I.R. grant to the University of Port Elizabeth Beach Studies Program under the direction of A. McLachlan. Members of the sandy beach group provided much needed assistance; special thanks goes to Trevor Molloy and Ted Donn for help in the field and to Maggie Hawkins for preparing the figures

\section{LITERATURE CITED}

Ansell, A. D., Trueman, E. R. (1973). The energy cost of migration of the bivalve Donax on tropical sandy beaches. Mar. Behav. Physiol. 2: 21-32

Bally, R. (1981). The ecology of three sandy beaches on the west coast of South Africa. Ph. D. thesis, University of Cape Town

Bally, R. (1983). Intertidal zonation on sandy beaches of the west coast of South Africa. Cah. Biol mar 24:85-103

Brown, A. C. (1982). The biology of sandy beach whelks of the genus Bullia (Nassariidae). Oceanogr. mar Biol. A. Rev. 20: 309-361

Dean, R. A. (1973). Heuristic models of sand transport in the surfzone. In: Proc. Conf. Engr. Dynamics in the Surf Zone, Sydney, p. 208-214

Komar, P. D., Quinn, W., Creech, C., Rea, C. C., LizarragaArciniega, J. R. (1976). Wave conditions and beach erosion on the Oregon coast. Ore. Bin. 38: 103-112

McArdle, S., McLachlan, A. (in press). Swash climate in a range of beach types: implications for macrobenthic fauna. $J$. coast. Res.

McIntyre, A. D., Munro, A. L. S. Steele, J. H. (1970). Energy flow on a sand ecosystem, In: Steele, J. H. (ed.) Marine food chains. Oliver and Boyd, Edinburgh, p. 19-31
McLachlan, A. (1979). Volumes of seawater filtered by East Cape sandy beaches. S. Afr J. Sci. 75: 75-79

McLachlan, A. (1982). A model for the estimation of water filtration and nutrient regeneration by exposed sandy beaches. Mar. environ. Res. 6: 37-47

McLachlan, A. (1983). Sandy beach ecology a review. In McLachlan, A., Erasmus, T (eds.) Sandy beaches as ecosystems. Junk, The Hague, p. 321-380

McLachlan, A. (1989). Water filtration by dissipative beaches Limnol. Oceanogr. 34: 774-780

McLachlan, A. (1990). Dissipative beaches and macrofauna communities on exposed intertidal sands. J. coast. Res. 6 : $57-71$

McLachlan, A., Eliot, I. G., Clarke, D. J. (1985). Water filtration through reflective microtidal beaches and shallow sublittoral sands and its implications for an inshore ecosystem in Western Australia. Estuar coast. Shelf Sci. 21: 91-104

McLachlan, A., Wooldridge, T., Dye, A. H. (1981). The ecology of sandy beaches in Southern Africa. S. Afr. J. Zool. 16: 219-231

McLachlan, A., Young, N. (1982). Effects of low temperature on the burrowing rates of four sandy beach molluscs. J. exp. mar Biol. Ecol. 65: 275-284

Riedl, R. J. (1971). How much seawater passes through sandy beaches? Int. Rev. gesamt. Hydrobiol. 56: 923-946

Riedl, R. J., Machan, R. (1972). Hydrodynamic patterns in Iotic intertidal sands and their bioclimatological implications. Mar Biol. 13: 179-209

Salvat, B. (1964). Les conditions hydrodynamiques interstitielle des sediment meubles intertidaux et la repartition verticale de la jenne endogée. C. R. Acad. Sci. Paris 259 $1567-1579$

Salvat, B. (1966). Eurydice pulchra Leach 1815 et Eurydice affinis Hansen 1905 (Isopodes: Cirolanidae). Taxonomie, ethologie, repartition verticale et cycle reproduction. Actes Soc. Linn. Bordeaux, Ser. A 193: 1-77

Salvat, B. (1967). La macrofauna carcinologique endogée des sediments meubles intertidaux (Tanaidaces, Isopodes et Amphipodes): ethologie, bionomie et cycle biologique. Mém. Mus. natn. Hist. nat., Paris (Ser A) 45: 1-275

Shepherd, R. A. (1985). Distribution of the juvenile southern mole crabs, Hippa australis Hale (Crustacea: Anomura: Huppidae) in relation to winter swashwater circulation and spring-tide excursions on a sandy beach. Hons. project, Dept of Geog., University of Western Australia

Short, S. D., Wright, L. D. (1983). Physical variability of sandy beaches. In: McLachlan, A., Erasmus, T. (eds.) Sandy beaches as ecosystems. Junk, The Hague, p. 133-144

Waddell, E. (1976). Swash-groundwater-beach profiles interactions. In: Davis, R. A., Ethington, R. E. (eds.) Beach and nearshore sedimentation. Soc. Econ. Palaeontol. Mineral., Oklahoma, Spec. Publ., p. 115-125

Wendt, G. E., McLachlan, A. (1985). Zonation and biomass of the intertidal macrofauna along a South African sandy beach. Cah. Biol. mar. 26: 1-14

Wright, L. D., Short, A. D., Nielsen, P. (1982). Morphodynamics of high energy beaches and surf zones: A brief synthesis. Coastal Studies Unit. Tech. Rep. No. 82/5. Coastal Studies Unit, University of Sydney, $64 \mathrm{p}$.

Manuscript first received: March 23, 1990

Revised version accepted: June 25, 1991 